BMJ Open

Ophthalmology

\title{
Prevalence of keratoconus in persons with Down syndrome: a review
}

\author{
Olav Kristianslund (D) , 1,2 Liv Drolsum ${ }^{1,2}$
}

To cite: Kristianslund 0 , Drolsum L. Prevalence of keratoconus in persons with Down syndrome: a review. BMJ Open Ophthalmology 2021;6:e000754. doi:10.1136/ bmjophth-2021-000754

Received 28 February 2021 Accepted 4 April 2021
Check for updates

(C) Author(s) (or their employer(s)) 2021. Re-use permitted under CC BY-NC. No commercial re-use. See rights and permissions. Published by BMJ.

${ }^{1}$ Department of Ophthalmology, Oslo University Hospital, Oslo, Norway

${ }^{2}$ Institute of Clinical Medicine, University of Oslo, Oslo, Norway

Correspondence to Dr Olav Kristianslund; olav. kristianslund@gmail.com

\section{ABSTRACT}

Purpose Keratoconus is a vision-threatening condition, and there is a need for knowledge about the occurrence in subgroups of the population. The progression of the disease can be effectively stopped, and vision may be restored, if keratoconus is diagnosed at an early stage. The purpose of this review was to evaluate the literature of the prevalence of keratoconus in persons with Down syndrome.

Methods We conducted a literature review of keratoconus prevalence in persons with Down syndrome. A thorough search was performed in Pubmed (Medline), and the quality of evidence was evaluated.

Results The literature review identified 20 relevant studies, which reported keratoconus in $0 \%-71 \%$ of persons with Down syndrome. These studies varied greatly in design, patient selection, sample sizes and mean age, and the quality of evidence concerning estimates for the prevalence of keratoconus was generally evaluated as low. Most studies that included adults reported high prevalences of keratoconus-in many studies more than 10 -fold the prevalence in the general population. No large screening studies in persons with Down syndrome were identified.

Conclusions The present review showed that the prevalence of keratoconus in persons with Down syndrome is higher than in the general population. However, estimates from previous studies vary widely. Screening for keratoconus in this group should be considered.

\section{INTRODUCTION}

Keratoconus is characterised by thinning and a conical shape of the cornea leading to refraction errors and visual complaints. ${ }^{1}$ As the disease progresses, the corrected distance visual acuity is affected. At this stage, further examinations are often performed, and corneal tomography usually leads to the diagnosis.

Keratoconus was previously considered quite rare, with a reported prevalence of 54.5 per 100000 population in an often-cited study from $1986 .^{2}$ However, some recent studies have reported markedly higher prevalences; $0.2 \%-0.3 \%$ in the general population ${ }^{34}$ and more than $1 \%$ in some subgroups. ${ }^{5-7}$ Higher rates may be a consequence of more sophisticated diagnostics and increased awareness of the disease in recent years. Additionally, the threshold for referral and more diligent follow-up of these patients are likely lowered as a result of corneal collagen crosslinking (CXL), which has been shown as a successful treatment for stopping the disease progression. ${ }^{8-11}$ The introduction of CXL has led to a decreased demand for keratoplasties in keratoconus patients. ${ }^{1112}$

Persons with Down syndrome have an increased risk of several medical diseases. Ocular conditions include epicanthus, strabismus, lens opacifications and refraction errors. ${ }^{13-15}$ An increased risk of keratoconus has also been mentioned, ${ }^{15-19}$ although the exact reason for this association remains unknown. Studies have found varying frequencies of keratoconus in persons with Down syndrome. While some have reported a markedly higher prevalence than in the general population, other studies have reported no keratoconus cases. ${ }^{13} 1516$ 18-30

In the literature, no clear consensus appears to have been established regarding the true prevalence of keratoconus in persons with Down syndrome. Many studies seem to be limited by small sample sizes, furthermore, prevalence estimates are affected by whether studies have examined subgroups of patients or specific age groups (eg, children). A thorough evaluation of these aspects seemed to be required. Knowledge about the occurrence of keratoconus in persons with Down syndrome is essential for both clinicians and policymakers, in terms of determining the threshold for referral to eye examination for individual patients, for resource allocation and for evaluating whether keratoconus screening should be recommended in this group. In this literature review, we aimed to investigate the prevalence of keratoconus in persons with Down syndrome as well as to evaluate the quality of the current knowledge.

\section{MATERIALS AND METHODS}

In this review, we conducted a literature search of all published articles that have presented original research with numbers and/or proportions of the occurrence of keratoconus in persons with Down syndrome. 
We used the following search strategy to find relevant publications on PubMed (Medline): ((keratoconus[Title/ Abstract]) AND (prevalence[Title/Abstract] OR incidence[Title/ Abstract])) AND Down syndrome[Title/Abstract]. An additional search was performed without the terms prevalence and incidence. We also searched the reference lists of the included articles, in case some relevant publications had not been identified. The search was restricted to Englishlanguage publications and had no time restrictions. It was conducted by two independent reviewers (OK and LD) and was finished in November 2020. The quality of evidence and risk of bias of the included studies were evaluated.

\section{RESULTS}

\section{Results of the literature search}

The main literature search yielded 21 articles, 13 of which reported rates of keratoconus in persons with Down syndrome. ${ }^{13} 1518-2224252730-32$ In the additional literature search with a total of 54 articles, we identified another six articles for inclusion. ${ }^{162326282933}$ Thus, a total of 19 articles met the inclusion criteria for the review. In addition, we have included results from our recently published nationwide register study of the keratoconus prevalence in persons with Down syndrome ${ }^{34}$ As shown in table 1 , the reported rates in these publications ranged from $0 \%$ to $71 \%$. Another three studies were considered relevant, although they did not quantify the rate of keratoconus: one study found a high proportion of astigmatism and myopia in persons with Down syndrome ${ }^{14}$; another found a steeper corneal curvature on topography in persons with Down syndrome compared with controls ${ }^{35}$ and a third showed that corneal topographic changes in persons with Down syndrome were more similar to mild keratoconus than in controls. ${ }^{36}$ Furthermore, a large retrospective longitudinal cohort study of keratoconus patients found an adjusted OR of 6.22 for Down syndrome. ${ }^{37}$

\section{Quality of evidence evaluation}

A quite high proportion of the included studies had small sample size in terms of determining the prevalence of keratoconus in persons with Down syndrome. The number of individuals with Down syndrome in the included studies ranged from 31 to 4342 (table 1). The studies varied in terms of whether they reported specific inclusion criteria in detail. Some studies did only include hospitalised patients. Seven studies focused on children. ${ }^{16} 2023-26$ Ten studies either did not include corneal tomography or did not comment on the use of such diagnostic instruments. ${ }^{18-21} 24-26$ 28-30 In general, higher rates $(>10 \%)$ were reported in studies that included corneal topography as standard. ${ }^{13151622} 23273132$ Our recently published study was the only one that included the whole population of a country. ${ }^{34}$ Still, its quality of evidence was limited by the lack of detailed clinical data. Two studies were screened for keratoconus in selected samples of the population with Down syndrome, ${ }^{22} 32$ otherwise, we identified no large population-based screening studies.

\section{DISCUSSION}

Persons with Down syndrome have an increased risk of developing keratoconus. ${ }^{17-19}$ Our literature search identified several studies that have reported increased rates in this population-in one study as high as $71 \% .^{31}$ However, previous studies vary greatly; furthermore, their estimates have primarily been based on small sample sizes and often on selected hospital populations or children. ${ }^{13} 1516$ 18-30 Only one study reported nationwide numbers, estimating a keratoconus prevalence of $5.5 \%$ among persons with Down syndrome. ${ }^{34}$

Most previous studies have estimated a keratoconus prevalence in the range of 17.5-86 per 100000 in general populations. ${ }^{2}{ }^{38-42}$ However, markedly higher numbers have been reported in some recent studies of general populations, with an estimated prevalence of $0.2 \%$ in Norway, ${ }^{4} 0.3 \%$ in the Netherlands ${ }^{3}$ and $1.2 \%$ in a younger population in Australia. ${ }^{7}$ Furthermore, even higher rates have been found in subgroups of the population in India, Jerusalem, New Zealand and Saudi Arabia. ${ }^{5} 6344$ Although knowledge is limited concerning the aetiology of keratoconus, a number of publications have indicated that specific conditions are associated with an increased risk, including atopy, allergy, eye rubbing, Leber's congenital amaurosis, mitral valve prolapse and connective tissue disease. ${ }^{1745} 46$ In addition, an association with Down syndrome has been clearly demonstrated. ${ }^{17-19}$

Down syndrome is caused by an extra copy of chromosome 21. The occurrence seems to vary across countries, in the range of $0.7-1.4$ per 1000 live births. ${ }^{478}$ The proportion in the general population is expected to be slightly lower, as persons with Down syndrome have a shorter life expectancy. ${ }^{49}$ Rates of approximately 0.8 per 1000 people in the general population have been reported. ${ }^{491}$ Suggested links with keratoconus are collagen-related abnormalities and that keratoconus is linked to chromosome 21. ${ }^{17} 45$ Additionally, it has been argued that Down syndrome is associated with more eye rubbing and possibly also a higher frequency of atopy. ${ }^{15} 17304552$ Moreover, a thinner cornea has been found in the eyes of persons with Down syndrome without manifest keratoconus. $^{1516}$

This literature review identified studies that have reported keratoconus in as many as $8 \%-36 \%$ of persons with Down syndrome ${ }^{15} 16 \quad 1822 \quad 2327-3033$ and in one study even in $71 \% .^{13}$ However, several of these studies had small sample sizes and a biased patient selection (table 1). Furthermore, other studies have reported no keratoconus in persons with Down syndrome. ${ }^{19} 202526$ This inconsistency is likely due to study design, completeness of the data, disease criteria, the diagnostics used and ethnicity (it has been speculated that the proportion of keratoconus is considerably lower in Asians with Down syndrome) ${ }^{53}$ In addition, age seems to be an important factor to the variation in prevalence, as several of the studies (especially those from Asia) seem to have only included children, whereas keratoconus usually develops in adolescence or early adulthood. Furthermore, corneal 
Table 1 Proportions with keratoconus in persons with Down syndrome (studies identified by literature review)

\begin{tabular}{|c|c|c|c|c|c|}
\hline & n DS & n (\%) KC & Location & CT & Patient group and age \\
\hline Walsh $^{18}$ & 91 & $7(8 \%)$ & Sweden & No & $\begin{array}{l}\text { Institutionalised mentally retarded persons } \\
\text { (5-60 years). }\end{array}$ \\
\hline Wong and $\mathrm{Ho}^{19}$ & 140 & $0(0 \%)$ & Hong Kong & No & Children (3 months-13 years) in hospital. \\
\hline Van Allen et $a l^{29}$ & 38 & $6(15.8 \%)$ & USA & No & Adults (30-68 years old) in residential centre. \\
\hline Haugen et $a l^{15}$ & 47 & $5(10.6 \%)$ & Norway & Yes & Case-control study (all ages) \\
\hline Kim et $a l^{25}$ & 123 & $0(0 \%)$ & Korea & No & $\begin{array}{l}\text { Children ( } 6 \text { months-14 years), non- } \\
\text { institutionalised. }\end{array}$ \\
\hline Van Splunder et $\left.a\right|^{30}$ & 409 & $36(9 \%)$ & Netherlands & No & Cross-sectional survey. Adults ( $\geq 18$ years) \\
\hline $\begin{array}{l}\text { Liza-Sharmini et } \\
a^{26}\end{array}$ & 60 & $0(0 \%)$ & Malaysia & $\mathrm{No}^{*}$ & Children (1 month-17 years) in hospital. \\
\hline Fimiani et $a l^{20}$ & 157 & $0(0 \%)$ & Italy & No & Children (1 month-18 years) in hospital. \\
\hline Karlica et $a l^{24}$ & 153 & $2(1.3 \%)$ & Split-Dalmatia & No & Children (0-18 years). \\
\hline Fong et $a l^{21}$ & 91 & $1(1 \%)$ & Hong Kong & Not & Cross-sectional survey. Adults ( $\geq 18$ years) \\
\hline Aslan et $\mathrm{al}^{16}$ & 27 & $21.1 \%$ (11 eyes) & Helsinki & Yes & $\begin{array}{l}\text { Children (5-12 years). Clinical trial. Identified } \\
\text { early subclinical keratoconus. }\end{array}$ \\
\hline Li et $a l^{33}$ & 20 & $36.3 \%$ (12 eyes) & Hong Kong & Yesł & $\begin{array}{l}\text { Adult patients scheduled for cataract surgery } \\
\text { (tertiary eye hospital) }\end{array}$ \\
\hline Real de Asua et $a l^{28}$ & 144 & $10(7 \%)$ & Spain & Unknown & $\begin{array}{l}\text { Retrospective review of medical records. } \\
\text { Adults (17-65 years) }\end{array}$ \\
\hline Alio et $a l^{13}$ & $59 \S$ & $42(71.3 \%)$ & $\begin{array}{l}\text { Spain and } \\
\text { Egypt }\end{array}$ & Yes & $\begin{array}{l}\text { Multicentre case-control study. Age } 3 \\
\text { months- } 60 \text { years. }\end{array}$ \\
\hline Marsack et al ${ }^{27}$ & 140 & $\begin{array}{l}11.8 \%-20.8 \% \text { १ी } \\
\text { (26-46 eyes) }\end{array}$ & USA & Yes & Case-control study. Age 8-55 years \\
\hline Hashemi et $a l^{22}$ & 226 & $28(12.4 \%)$ & Iran & Yes & $\begin{array}{l}\text { Population-based cohort study. Age 10-30 } \\
\text { years. }\end{array}$ \\
\hline Imbornoni et $a^{23}$ & 31 & $10(32 \%)$ & USA & Yes & Children/young adults (4-24 years) in hospital. \\
\hline Mathan et $a l^{32}$ & 98 & $30(30.6 \%)^{* *}$ & New Zealand & Yes & $\begin{array}{l}\text { Screening of paralympics athletes (age 15-53 } \\
\text { years) }\end{array}$ \\
\hline Bermudez et $a l^{31}$ & 1207 & $331(27.2 \%)$ & Brazil & Yes $\ddagger$ & $\begin{array}{l}\text { Retrospective review of medical records. } \\
\text { Adults (all ages) }\end{array}$ \\
\hline $\begin{array}{l}\text { Kristianslund and } \\
\text { Drolsum }^{34}\end{array}$ & 4342 & $238(5.5 \%)$ & Norway & Yest† & Population-based register study. All ages. \\
\hline
\end{tabular}

*Placido disc used to detect keratoconus.

tCorneal thickness measured.

łwhen $\mathrm{KC}$ suspected and the patient cooperated.

$\S$ Number of patients that cooperated with eye examination.

IProportion above threshold on detection metric (two types used).

${ }^{* *}$ Presents several numbers.

††Performed in many cases when indicated and the patient cooperated, however, proportion unknown.

$\mathrm{CT}$, corneal topography/tomography; DS, Down Syndrome; KC, keratoconus; n, number.

topography was not always included as part of the ocular examination. This review identified rates in the range of $10.6 \%-71.3 \%$ in studies that included corneal topography as part of the examination of mainly adult patients (table 1). 1315162223273132

In a study from Norway, we reported a national prevalence of keratoconus in persons with Down syndrome using data from a nationwide patient registry, ${ }^{34}$ thereby avoiding the risk of selection bias. We found a keratoconus rate of $5.5 \%$ in this subgroup, which is 30 times the estimated keratoconus prevalence in the general Norwegian population. ${ }^{4}$ The Norwegian Patient Registry is nationwide and mandatory for public specialist care; thus, making it possible to study the national occurrence of keratoconus in persons with Down syndrome and compare it with the corresponding rate in the general population. However, even in national register studies, some uncertainty remains as to whether patients have been correctly coded. In addition, the true prevalence of keratoconus in patients with Down syndrome is probably higher, as no routine screening is performed for this condition.

Few other studies of keratoconus in persons with Down syndrome have been carried out in Northern 
Europe. ${ }^{15} 1618$ A case-control study by Haugen et $a l^{15}$ found a thinner cornea, higher keratometry values and more keratoconus in the Down syndrome group, as 5 out of $47(11 \%)$ individuals with Down syndrome had keratoconus, compared with 1 out of $51(2 \%)$ controls. In studies from various other regions throughout the world, lower proportions than the one we found in Norway have been reported in young patients, ${ }^{20}{ }^{24-26}$ whereas higher proportions have often been reported in selected hospital populations. ${ }^{13} 18222829$ In a study from Brazil, Bermudez $e t a l^{31}$ reviewed the medical records of 1207 patients with Down syndrome and found a keratoconus rate of $27.2 \%$. They describe an ophthalmological outpatient clinic for Down syndrome patients, which included corneal topography if keratoconus was suspected and the patient cooperated. Thus, their numbers possibly approaches a realistic prevalence if screening for keratoconus is performed in persons with Down syndrome.

It seems reasonable to suspect a substantial number of undiagnosed cases of keratoconus, particularly in persons with Down syndrome, since the detection of this eye condition depends on adequate communication of symptoms, timely referral and good cooperation during the eye examinations. Early keratoconus may be challenging to diagnose in the slit lamp only, and cooperation with corneal tomography is often a challenge in persons with Down syndrome. Retinoscopy may be valuable by searching for abnormal motions of the retinoscopy reflex. ${ }^{15}$

Several studies from general populations have found a male predominance for keratoconus, ${ }^{36}{ }^{40} 54-56$ although this finding has not been consistent. ${ }^{25}{ }^{59}{ }^{57}$ In this literature review, we identified one publication that found a similar gender distribution among persons with Down syndrome and keratoconus, ${ }^{22}$ which is consistent with our recent publication, ${ }^{34}$ otherwise, the gender distribution does not seem to have been in focus. There seem to be slightly more male than female persons with Down syndrome. ${ }^{58}$ We were, therefore, surprised to find a similar gender distribution for keratoconus in persons with Down syndrome in our study from Norway, as we have previously identified a quite pronounced male predominance for keratoconus in general in the total Norwegian population. ${ }^{4}$ Several predisposing factors seem to influence the development of keratoconus, and we hypothesise that the predominant factor in persons with Down syndrome is not related to gender or hormonal factors. However, this is speculation, and further research is needed.

Results from this literature review indicate a considerably higher proportion of keratoconus in persons with Down syndrome compared with the general population. An implication from this finding is that screening should be considered for this group, ${ }^{3059}$ especially since several of these patients are less able to communicate their symptoms. Health economic aspects should be included in such evaluations. Marsack et $a l^{27}$ demonstrated keratoconus suspect findings in $11.8 \%-20.8 \%$ of eyes of persons with Down syndrome, using two detection metrics on corneal topographies. If keratoconus is detected, and
CXL treatment is performed in early stages, a good visual acuity can hopefully be maintained. Furthermore, this may avoid persons reaching advanced stages, where corneal transplantation with a long postoperative follow-up may become necessary; a treatment that is particularly complicated in Down syndrome patients. ${ }^{60} \mathrm{~A}$ considerable proportion of persons with Down syndrome has visual impairment, ${ }^{21}$ and advanced stage keratoconus is likely one of the reasons.

In conclusion, the present review found a great variation in the reported prevalence of keratoconus in persons with Down syndrome; however, most studies of adolescents and adults reported a markedly higher prevalence than in the general population. Still, it seems likely that a significant number of keratoconus cases in persons with Down syndrome are undiagnosed. This indicates that screening for keratoconus in these individuals should be considered, to detect candidates for CXL treatment at an early stage. Also, large screening studies in persons with Down syndrome using slit lamp examinations and corneal tomography in cooperative individuals could provide more answers regarding the true prevalence.

Funding The authors have not declared a specific grant for this research from any funding agency in the public, commercial or not-for-profit sectors.

Competing interests None declared.

Patient consent for publication Not required.

Provenance and peer review Not commissioned; externally peer reviewed.

Data availability statement All data relevant to the study are included in the article or uploaded as supplementary information. Data for this review article is included in the article and available in public databases.

Open access This is an open access article distributed in accordance with the Creative Commons Attribution Non Commercial (CC BY-NC 4.0) license, which permits others to distribute, remix, adapt, build upon this work non-commercially, and license their derivative works on different terms, provided the original work is properly cited, appropriate credit is given, any changes made indicated, and the use is non-commercial. See: http://creativecommons.org/licenses/by-nc/4.0/.

\section{ORCID iD}

Olav Kristianslund http://orcid.org/0000-0003-3390-9811

\section{REFERENCES}

1 Gomes JAP, Tan D, Rapuano CJ, et al. Global consensus on keratoconus and ectatic diseases. Cornea 2015;34:359-69.

2 Kennedy $\mathrm{RH}$, Bourne WM, Dyer JA. A 48-year clinical and epidemiologic study of keratoconus. Am J Ophthalmol 1986;101:267-73.

3 Godefrooij DA, de Wit GA, Uiterwaal CS, et al. Age-Specific incidence and prevalence of keratoconus: a nationwide registration study. Am J Ophthalmol 2017;175:169-72.

4 Kristianslund O, Hagem AM, Thorsrud A, et al. Prevalence and incidence of keratoconus in Norway: a nationwide register study. Acta Ophthalmol 2020;2018.

5 Jonas JB, Nangia V, Matin A, et al. Prevalence and associations of keratoconus in rural Maharashtra in central India: the central India eye and medical study. Am J Ophthalmol 2009;148:760-5.

6 Millodot M, Shneor E, Albou S, et al. Prevalence and associated factors of keratoconus in Jerusalem: a cross-sectional study. Ophthalmic Epidemiol 2011;18:91-7.

7 Chan E, Chong EW, Lingham G, et al. Prevalence of keratoconus based on scheimpflug imaging. Ophthalmology 2021;128:515-21.

8 Hersh PS, Greenstein SA, Fry KL. Corneal collagen crosslinking for keratoconus and corneal ectasia: one-year results. J Cataract Refract Surg 2011;37:149-60.

9 Hersh PS, Stulting RD, Muller D, et al. United States multicenter clinical trial of corneal collagen crosslinking for keratoconus treatment. Ophthalmology 2017;124:1259-70. 
10 Wollensak G, Spoerl E, Seiler T. Riboflavin/ultraviolet-a-induced collagen crosslinking for the treatment of keratoconus. Am J Ophthalmol 2003;135:620-7.

11 Sandvik GF, Thorsrud A, Råen M, et al. Does corneal collagen cross-linking reduce the need for keratoplasties in patients with keratoconus? Cornea 2015;34:991-5.

12 Godefrooij DA, Gans R, Imhof SM, et al. Nationwide reduction in the number of corneal transplantations for keratoconus following the implementation of cross-linking. Acta Ophthalmol 2016;94:675-8.

13 Alio JL, Vega-Estrada A, Sanz P, et al. Corneal morphologic characteristics in patients with Down syndrome. JAMA Ophthalmol 2018;136:971-8

14 da Cunha RP, Moreira JB, Moreira JB. Ocular findings in Down's syndrome. Am J Ophthalmol 1996;122:236-44.

15 Haugen $\mathrm{OH}$, Høvding G, Eide GE. Biometric measurements of the eyes in teenagers and young adults with Down syndrome. Acta Ophthalmol Scand 2001;79:616-25.

16 Aslan L, Aslankurt M, Yüksel E, et al. Corneal thickness measured by scheimpflug imaging in children with Down syndrome. J Aapos 2013;17:149-52.

17 Rabinowitz YS. Keratoconus. Surv Ophthalmol 1998;42:297-319.

18 Walsh SZOE. Keratoconus and blindness in 469 institutionalised subjects with Down syndrome and other causes of mental retardation. J Ment Defic Res 1981;25:243-51.

19 Wong V, Ho D. Ocular abnormalities in Down syndrome: an analysis of 140 Chinese children. Pediatr Neurol 1997;16:311-4.

20 Fimiani F, lovine A, Carelli R, et al. Incidence of ocular pathologies in Italian children with Down syndrome. Eur J Ophthalmol 2007;17:817-22.

21 Fong AHC, Shum J, Ng ALK, et al. Prevalence of ocular abnormalities in adults with Down syndrome in Hong Kong. $\mathrm{Br} J$ Ophthalmol 2013;97:423-8.

22 Hashemi H, Miraftab M, Amanzadeh K, et al. Keratoconus detection by novel indices in patients with Down syndrome: a cohort population-based study. Jpn J Ophthalmol 2020;64:285-91.

23 Imbornoni LM, Wise RE, Taravella MJ, et al. Keratoconus and corneal morphology in patients with Down syndrome at a pediatric hospital. J Aapos 2020;24:140.e1-5.

24 Karlica D, Skelin S, Culic V. The ophthalmic anomalies in children with Down syndrome in Split-Dalmatian County. Coll Antropol 2011;35:1115-8.

$25 \mathrm{Kim} \mathrm{JH}$, Hwang J-M, Kim HJ, et al. Characteristic ocular findings in Asian children with Down syndrome. Eye 2002;16:710-4.

26 Liza-Sharmini AT, Azlan ZN, Zilfalil BA. Ocular findings in Malaysian children with Down syndrome. Singapore Med J 2006;47:14-19.

27 Marsack JD, Benoit JS, Kollbaum PS, et al. Application of topographical keratoconus detection metrics to eyes of individuals with Down syndrome. Optom Vis Sci 2019;96:664-9.

28 Real de Asua D, Quero M, Moldenhauer F, et al. Clinical profile and main comorbidities of Spanish adults with Down syndrome. Eur J Intern Med 2015;26:385-91.

29 van Allen MI, Fung J, Jurenka SB. Health care concerns and guidelines for adults with Down syndrome. Am J Med Genet 1999;89:100-10.

30 van Splunder J, Stilma JS, Bernsen RMD, et al. Prevalence of ocular diagnoses found on screening 1539 adults with intellectual disabilities. Ophthalmology 2004:111:1457-63.

31 Bermudez BEBV, de Souza do Amaral ME, da Silva Gomes C, et al. Ophthalmological abnormalities in Down syndrome among Brazilian patients. Am J Med Genet A 2020;182:2641-5.

32 Mathan JJ, Gokul A, Simkin SK, et al. Topographic screening reveals keratoconus to be extremely common in Down syndrome. Clin Exp Ophthalmol 2020;48:1160-7.

33 EY L, Chan TC, Lam NM. Cataract surgery outcomes in adult patients with Down's syndrome. Br J Ophthalmol 2014;98:1273-6.

34 Kristianslund O, Drolsum L. Prevalence of keratoconus in persons with Down syndrome in a national registry in Norway. JAMA Netw Open 2021;4:e210814.

35 Vincent AL, Weiser BA, Cupryn M, et al. Clinical science. computerized corneal topography in a paediatric population with Down syndrome. Clin Exp Ophthalmol 2005;33:47-52.
36 Vega-Estrada A, Fariselli C, Alio JL. Posterior corneal features in patients with Down syndrome and their relation with keratoconus. $\mathrm{Br}$ J Ophthalmol 2020;104:1683-9.

37 Woodward MA, Blachley TS, Stein JD. The association between sociodemographic factors, common systemic diseases, and keratoconus: an analysis of a nationwide Heath care claims database. Ophthalmology 2016;123:457-65.

38 Bak-Nielsen S, Ramlau-Hansen $\mathrm{CH}$, Ivarsen A, et al. Incidence and prevalence of keratoconus in Denmark - an update. Acta Ophthalmol 2019;97:752-5.

39 Hwang S, Lim DH, Chung T-Y. Prevalence and incidence of keratoconus in South Korea: a nationwide population-based study. Am J Ophthalmol 2018;192:56-64.

40 Ihalainen A. Clinical and epidemiological features of keratoconus genetic and external factors in the pathogenesis of the disease. Acta Ophthalmol Suppl 1986;178:1-64.

41 Lee HK, Jung EH, Cho B-J. Epidemiological association between systemic diseases and keratoconus in a Korean population: a 10year nationwide cohort study. Cornea 2020;39:348-53.

42 Nielsen K, Hjortdal J, Aagaard Nohr E, et al. Incidence and prevalence of keratoconus in Denmark. Acta Ophthalmol Scand 2007;85:890-2.

43 Papali'i-Curtin AT, Cox R, Ma T, et al. Keratoconus prevalence among high school students in New Zealand. Cornea 2019;38:1382-9.

44 Torres Netto EA, Al-Otaibi WM, Hafezi NL, et al. Prevalence of keratoconus in paediatric patients in Riyadh, Saudi Arabia. $\mathrm{Br} J$ Ophthalmol 2018;102:1436-41

45 Edwards M, McGhee CNJ, Dean S. The genetics of keratoconus. Clin Exp Ophthalmol 2001;29:345-51.

46 Lin KK, Lee JS, Hou CH. The sociodemographic and risk factors for keratoconus: nationwide matched case-control study in Taiwan, 1998-2015. Am J Ophthalmol 2020

47 Malt EA, Dahl RC, Haugsand TM. Health and disease in adults with Down syndrome. Tidsskr Nor Laegeforen 2013;133:290-4.

48 de Graaf G, Haveman M, Hochstenbach R, et al. Changes in yearly birth prevalence rates of children with Down syndrome in the period 1986-2007 in the Netherlands. J Intellect Disabil Res 2011;55:462-73.

49 Presson AP, Partyka G, Jensen KM, et al. Current estimate of Down syndrome population prevalence in the United States. J Pediatr 2013;163:1163-8.

50 Zhu JL, Hasle H, Correa A, et al. Survival among people with Down syndrome: a nationwide population-based study in Denmark. Genet Med 2013;15:64-9.

51 de Graaf G, Buckley F, Skotko BG. Estimation of the number of people with Down syndrome in the United States. Genet Med 2017;19:439-47.

52 Haugen $\mathrm{OH}$. Keratoconus in the mentally retarded. Acta Ophthalmol 1992;70:111-4

53 Kok YO, Tan GFL, Loon SC. Review: keratoconus in Asia. Cornea 2012;31:581-93.

54 Kristianslund O, Hagem AM, Thorsrud A, et al. Prevalence and incidence of keratoconus in Norway: a nationwide register study. Acta Ophthalmol 2020;2018. doi:10.1111/aos.14668. [Epub ahead of print: 16 Nov 2020].

55 Fink BA, Wagner H, Steger-May K, et al. Differences in keratoconus as a function of gender. Am J Ophthalmol 2005;140:459-68.

56 Pearson AR, Soneji B, Sarvananthan N, et al. Does ethnic origin influence the incidence or severity of keratoconus? Eye 2000;14:625-8.

57 Assiri AA, Yousuf BI, Quantock AJ, et al. Incidence and severity of keratoconus in Asir Province, Saudi Arabia. Br J Ophthalmol 2005;89:1403-6.

58 Stancliffe RJ, Lakin KC, Larson SA, et al. Demographic characteristics, health conditions, and residential service use in adults with Down syndrome in 25 U.S. states. Intellect Dev Disabil 2012;50:92-108

59 Haugen $\mathrm{OH}$, Hovding G, Riise R. Ocular changes in Down syndrome]. Tidsskr Nor Laegeforen 2004;124:186-8.

60 Wroblewski KJ, Mader TH, Torres MF, et al. Long-Term graft survival in patients with Down syndrome after penetrating keratoplasty. Cornea 2006;25:1026-8. 